\title{
Laboreal
}

Volume $3 \mathrm{~N}^{\circ} 1$ | 2007

Varia

\section{A psicologia em França de 1870 a 1940, de uma ciência aplicada a uma disciplina universitária}

La psicología en Francia de 1870 a 1940, de una ciencia aplicada a una asignatura universitaria

La psychologie en France de 1870 à 1940 : d'une science appliquée à une discipline universitaire

Psychology in France from 1870 to 1940: from an applied science to a university discipline

\section{Régis Ouvrier-Bonnaz}

Tradutor: Liliana Cunha

\section{(2) OpenEdition}

\section{Journals}

\section{Edição electrónica}

URL: http://journals.openedition.org/laboreal/13016

DOI: $10.4000 /$ laboreal. 13016

ISSN: 1646-5237

\section{Editora}

Universidade do Porto

\section{Refêrencia eletrónica}

Régis Ouvrier-Bonnaz, " A psicologia em França de 1870 a 1940, de uma ciência aplicada a uma disciplina universitária », Laboreal [Online], Volume 3 N$^{0} 1$ | 2007, posto online no dia 01 julho 2007, consultado o 24 setembro 2020. URL : http://journals.openedition.org/laboreal/13016 ; DOI : https:// doi.org/10.4000/laboreal.13016

Este documento foi criado de forma automática no dia 24 setembro 2020.

Laboreal está licenciado com uma Licença Creative Commons - Atribuição-NãoComercial 4.0 Internacional. 


\title{
A psicologia em França de 1870 a 1940, de uma ciência aplicada a uma disciplina universitária
}

\author{
La psicología en Francia de 1870 a 1940, de una ciencia aplicada a una \\ asignatura universitaria \\ La psychologie en France de 1870 à 1940 : d'une science appliquée à une \\ discipline universitaire \\ Psychology in France from 1870 to 1940: from an applied science to a university \\ discipline
}

\section{Régis Ouvrier-Bonnaz}

Tradução : Liliana Cunha

\section{NOTA DO EDITOR}

XV Semana da Associação de Estudantes da Faculdade de Psicologia e de Ciências da Educação da Universidade do Porto, "Contextos".

\section{Nota Bibliográfica}

1 Régis Ouvrier-Bonnaz tem sido sucessivamente conselheiro de orientação, director de centro de informação e de orientação, professor num IUFM (Institut Universitaire de Formation de Maîtres), seguidamente responsável pela formação em orientação de professores do segundo grau e coordenador de um dispositivo de valorização e de formalização de inovações pedagógicas na Reitoria da Academia de Créteil, organismo da Educação Nacional. Membro durante uma dezena de anos da equipa de clínica da actividade dirigida por Yves Clot, no laboratório de psicologia do trabalho do CNAM[1] em Paris, ele é actualmente membro da equipa de psicologia da orientação do INETOP, 
deste mesmo CNAM, onde ensina a análise e a história do trabalho, a história da orientação e das instituições de formação. O seu percurso atípico, no espaço universitário de hoje, é significativo do papel durante muito tempo desempenhado pelo pessoal procedente dos serviços de orientação no desenvolvimento da psicologia em França.

2 As suas pesquisas organizam-se em torno de duas temáticas. A primeira refere-se à forma como a questão do trabalho é abordada na escola, de um ponto de vista histórico e de um ponto de vista didáctico e psicológico, no âmbito das actividades de orientação e de ensino propostas aos alunos do ensino básico e secundário. A segunda temática diz respeito à análise de situações de trabalho real, sob o ângulo do colectivo, como recurso à disposição dos profissionais para trabalhar, analisar a sua actividade e a desenvolver. Estas pesquisas situam-se no cruzamento de uma psicologia que privilegia a actividade (Clot, 1999; Léontiev, 1984) e as didácticas das disciplinas escolares onde a noção de prática social de referência (Martinand, 1986) é questionada. Elas visam construir uma didáctica da informação profissional no campo do trabalho e da orientação.

Para dar conta da orientação dos seus trabalhos no cruzamento da psicologia do trabalho e da psicologia da orientação, podemos realçar nas suas publicações recentes: "La découverte professionnelle", em co-autoria com Alain Crindal[2] ; um artigo "La référence au travail en classe de technologie: un débat de métier", publicado na revista electrónica @ctivités (vol III, 2, 2006); um artigo "Connaissance de soi et connaissance du travail dans la perspective d'une didactique de l'orientation scolaire: une approche par la coanalyse de l'activité des élèves", editada na Revue Française de Pédagogie (141, 2002); e ainda o número da revista Education Permanente editado em Junho de 2007, coordenado com Bernard Prot, consagrado às actividades de orientação e ao desenvolvimento dos ofícios.

Em França, no fim do século XIX, os primórdios da psicologia coincidem com a vontade de alguns investigadores, procedentes de disciplinas universitárias instituídas, como a medicina e a biologia, e agrupados em algumas instituições, de encontrar soluções científicas para questões de ordem social no domínio do trabalho e da formação profissional. No início, contrariamente à maioria das ciências, a psicologia é primeiro uma psicologia aplicada antes de ser uma disciplina de investigação. Uma corrente de ideias progressistas, de homens de ciência e de instituições de investigação aplicada: eis traçado, brevemente, o plano da minha conferência. Tal abordagem tem o mérito de ser transponível a outros países para favorecer estudos comparativos sobre a criação e o desenvolvimento da psicologia enquanto disciplina.

\section{A sociedade francesa da segunda metade do século XIX entre moral religiosa e racionalidade científica}

5 Na primeira parte do século XIX, a psicologia, essencialmente de natureza filosófica, quer-se antes de tudo introspectiva e especulativa. Ela assenta sobre uma abordagem reflexiva onde os comportamentos não são estudados como tal. Os factos de consciência são separados da realidade e a capacidade de cada um fazer aquilo que faz é ainda amplamente considerado como um dado divino incompreensível. O conhecimento do homem releva essencialmente da metafísica. Em Inglaterra, descrevendo o mecanismo da evolução das espécies, Darwin faz abalar os dogmas religiosos sobre a origem do homem e o seu desenvolvimento. Em França, na mesma época, Auguste Comte atribui à 
ciência o papel de unificação social, anteriormente confiado à religião. A ciência deve permitir fundar racionalmente a ordem social. 0 positivismo de Comte visa estudar como os factos nascem e se desenrolam, trata-se de os juntar para a eles nos submetermos. Este programa tem uma influência incontestável na aparição e no desenvolvimento de uma psicologia científica, embora Comte não tenha previsto lugar para a psicologia na sua classificação das ciências - a psicologia estava totalmente

reduzida à biologia. Neste contexto, um médico neuropsiquiatra, Théodore Ribot, criador em 1889 do primeiro laboratório de psicologia na Sorbonne, defende o princípio de uma psicologia científica, cujo programa esboça a partir de 1870. Este programa é subsidiário de duas grandes correntes que ele se esforça por promover, dando-as a conhecer em França. A primeira corrente, próxima do modelo orgânico, está ligada à abordagem experimental do psicólogo alemão Wundt, que sistematiza o problema das relações entre o espírito e a matéria estudando a actividade mental na sua duração e calculando a intensidade das sensações e o seu tempo de reaç̧ão. Para este autor, o aparelho psíquico não funciona como um mecanismo, mas como um conjunto orgânico cujas reaç̧ões são originais e, por conseguinte, irredutíveis às acções que as desencadeiam. A segunda corrente é a corrente evolucionista inglesa de Darwin e Spencer, que postula que as diferenças individuais são suficientemente importantes para provocar diferenças apreciáveis de possibilidades de sobrevivência e que afirma, pelo menos à escala estatística, o carácter hereditário da evolução. Galton, primo de Darwin, tenta então pôr em evidência, a partir do estudo de um grande número de indivíduos, as bases empíricas da teoria da espécie humana avaliando a amplitude das diferenças humanas em tarefas sensório-motoras. $O$ interesse do evolucionismo é de ter permitido compreender que os factos psicológicos tinham um passado e um futuro, por conseguinte, uma história, mas faltava ainda mostrar que esta última tinha um sentido.

O papel social dos cientistas: ideal republicano e justificação científica

8 A ciência impõe progressivamente o seu papel unificador e de regulador social e volta a questionar o papel da religião no que diz respeito à organização da sociedade. A biologia e a fisiologia são o instrumento de reforma da sociedade: Galton fala então de um clero científico. Em França, os promotores da escola obrigatória e laica, cujo objectivo é de favorecer o acesso de todas as crianças aos saberes de base e desenvolver os ideais de igualdade e de justiça social da III República (18701940)[3], falam de religião da humanidade[ [4] (Legrand, 1961). Nessa lógica, a psicologia tenta alinhar-se com as ciências da natureza para encontrar no homem as leis que regem os fenómenos naturais. Para a psicologia tradicional, procedente da filosofia, as faculdades inscreviam-se apenas entre as possibilidades abstractas. É agora ao nível próprio do real que a psicologia procura definir as eventualidades do comportamento. Dois grandes temas de investigação aplicada vão impor-se: a adaptação do homem ao trabalho e a selecção profissional ou escolar. A medida dos fenómenos psicológicos, susceptível de permitir estudar a afectação e a adaptação do homem à sua actividade profissional, implica que se encontre um conceito que venha dar corpo a esta adaptação. Este conceito será o de aptidão. As primeiras aplicações da psicologia aplicada assentam no fabrico de provas[5], susceptíveis de ajudar no diagnóstico destas aptidões, e o primeiro ofício da psicologia em França consiste em determinar a medida das aptidões requeridas para o exercício deste ou daquele ofício ou o seguimento de uma via de formação profissional. 
O primeiro quadro conceptual da psicologia aplicada no âmbito do trabalho e da orientação é conhecido: os indivíduos diferenciam-se por aptidões hereditárias estreitamente específicas. Trata-se de favorecer o ajustamento das aptidões do sujeito às exigidas pelos ofícios e de contribuir assim para que cada um ocupe o seu lugar, para a felicidade de todos (Huteau \& Lautrey, 1979). Essa preocupação está igualmente presente no espaço escolar deste início de século, como o testemunha o prefácio de Alfred Binet, no Ano Psicológico em 1908, a propósito dos estudos que estiveram na origem da construção da Escala métrica da inteligência:

"o alcance destes estudos ultrapassa a pedagogia, porque encararemos em particular as aptidões relativamente aos ofícios que os sujeitos estão destinados a exercer... pensamos que neste domínio, podemos fazer muito para melhorar as relações dos trabalhadores e dos patrões, e para ajudar à solução da questão operária, alertando as crianças, desde a escola, para as profissões para as quais elas estão mais aptas, e diminuindo assim, por esta profilaxia profissional, o número de sujeitos mal adaptados, que se tornam necessariamente desclassificados, infelizes ou insubmissos" (1908, p.VI).

O quadro que funda a aceitação da selecção profissional e es-

colar no âmbito da psicologia aplicada ao trabalho ganha forma na ideia de uma sociedade ideal, organizada segundo as leis da Razão, onde cada um encontraria o seu lugar. Num período onde se desenvolve consideravelmente a crise da aprendizagem e o acesso à profissão numa sociedade em plena mutação industrial e comercial, a medida científica das aptidões aparece como um progresso da razão. Neste contexto marcado pelos ideais de justiça e de adequação dos filósofos do século XVIII e pela filosofia positivista do século XIX, dois cientistas - Binet e Toulouse - vão desempenhar um papel importante. Binet, conhecido sobretudo pelos seus trabalhos sobre a escala métrica de inteligência, morre em 1911, com cinquenta e quatro anos. Binet desaparecido, o personagem central da história da psicologia aplicada francesa passa a ser Edouard Toulouse. O seu nome é associado à escola francesa de psicotécnica (Huteau, 2002).

O nascimento de uma psicologia aplicada, o papel de Toulouse (1865-1947): ideal-tipo do cientista republicano

o tempo no qual se inscreve a obra de Toulouse, psicólogo e psiquiatra, é o da III República. Toulouse é o protótipo do cientista republicano envolvido nas lutas sociais da sua época. Ele utiliza os contributos da ciência para tentar tornar a sociedade mais justa e racional, daí a sua preocupação de encontrar aplicações práticas para as descobertas e avanços científicos da biologia. Neste quadro, a biologia é um humanismo que pode ser considerado como a síntese de todas as ciências que têm o homem como objecto. Essa iniciativa que repousa sobre a ideia

de que as ciências biológicas fundam as acções sociais e em particular a política, é facilitada por uma actividade que ele não cessará de conduzir paralelamente à sua actividade científica: a de jornalista. Toulouse (1921) é, simultaneamente, médico alienista, investigador em psicologia e em psiquiatria, sociólogo, jornalista e escritor [ $\left.{ }^{6}\right]$. Para Toulouse, a ciência não é somente uma luta contra a ignorância, o preconceito, o dogma, o que a leva a opor-se às religiões. Ela é também a religião nova que deve conduzir e gerar o mundo. A justiça e a racionalidade explicam todos os compromissos de Toulouse: ciência e moral reforçam-se mutuamente. 
Os primeiros trabalhos de Toulouse reportam-se às relações da superioridade intelectual e da neuropatia, dito de outro modo, reportam-se à relação entre o génio e a loucura. Em 1896, publica uma primeira monografia sobre Emile Zola. Ele tira desse estudo sobre a superioridade intelectual dos artistas os elementos que lhe permitem pensar a questão da superioridade e da selecção profissional, objecto dos seus trabalhos desde há vários anos, como o testemunha esta citação:

“Interroguei contramestres de várias profissões, e aprendi que por toda a parte havia um pequeno número de trabalhadores que podiam tornar-se hábeis e aspirar aos primeiros empregos... Compreende-se sem esforço a utilidade do estudo que permitiria precisar quais são as qualidades necessárias para ter sucesso nesta ou naquela profissão e que permitiria também dar aos alunos que saem das escolas um conselho que impediria muitas falsas vocações e dirigiria cada um para o caminho onde pode ter mais sucesso."Alguns não têm sucesso porque são mal dotados, mas há outros que nada fazem de bom porque entraram numa profissão para o exercício da qual não tinham qualquer aptidão" (A Tribuna médica, n³1, 1887, p.601-602).

As três principais aplicações sociais práticas de Toulouse são

assim resumidas nesta citação: a análise do trabalho, a selecção profissional e a orientação. Para conduzir as suas investigações, teve que procurar apoios institucionais. Ele encontrá-los-á criando um laboratório de psicologia experimental num hospital dos arredores de Paris, para o qual foi nomeado em 1897.

o desenvolvimento de uma psicologia experimental : berço da investigação aplicada e da sua transmissão

Toulouse, nomeado médico-chefe no hospital de Villejuif, criou o que pode ser considerado como o primeiro laboratório francês de psicologia experimental. Este laboratório está associado à École Pratique des Hautes Études (Escola Prática de Altos Estudos) (EPHE). Piéron (1881-1962), que vai desempenhar um papel importante no que diz respeito ao desenvolvimento das instituições e da psicologia é para aí nomeado em 1900[7]. Ele escreveu em 1904, a pedido de Toulouse: Técnicas de psicologia experimental. Esse livro que reúne técnicas de observação experimental repousa sobre dois pontos de vista: a perspectiva associacionista que necessita de considerar o homem em todas as suas partes, isoladas umas das outras, e a vontade de atingir a maior precisão possível nas medidas. Esta abordagem opõese à de Binet que dirige, a partir de 1894, o laboratório de psicologia experimental da Sorbonne. A abordagem de Binet é funcionalista e global, "a inteligência existe apenas porque serve para alguma coisa. Ela serve para melhor nos adaptarmos ao meio físico da natureza e ao meio moral dos nossos semelhantes" (1909, p.133). As funções intelectuais que são as primeiras a desenvolver-se devem ser identificadas para estudar como elas se organizam, em que ordem elas aparecem e como elas se coordenam. Esta abordagem está na origem da escala métrica da inteligência, a famosa Binet e Simon, criada a pedido da comissão ministerial encarregada de estudar as medidas a tomar para assegurar os benefícios da instrução às crianças anormais. Esta escala, calculando o nível intelectual de um sujeito em relação aos sujeitos da sua idade, toma a forma de um teste de desenvolvimento. Ela permite calcular o quociente intelectual (QI). Este teste terá muita dificuldade em impor-se em França mas estará muito em voga nos Estados Unidos, onde servirá de base à construção do Terman-Merill, teste de nível intelectual, que será muito utilizado além-atlântico, em particular aquando da primeira guerra mundial, para a selecção de chefias militares. 

sua abordagem analítica e associacionista opõe-se à abordagem globalista e funcionalista da escala métrica. Daí o desinteresse de Piéron pelos trabalhos de Binet quando veio a assumir, em 1912, a sua sucessão no laboratório de psicologia da Sorbonne, após a sua morte prematura. Entre a abordagem de Binet e a de Piéron, há uma oposição de fundo. Piéron não procura justificar aquelas contradições no plano científico, mas fará por as ignorar, separando as suas investigações consagradas à fisiologia e as aplicações reservadas à orientação profissional. aplicações da psicologia em França e marcar o início da psicotécnica[ $\left.{ }^{8}\right]$. Esta técnica é considerada como científica pela simples razão, necessária e suficiente, de ela ser fundada em medidas, tão precisas e tão analíticas quanto possível, fornecidas por testes. Ela é julgada socialmente equitativa, já que a diversidade das orientações vai sendo determinada por constatações objectivas, apoiadas na diversidade das aptidões. Ela não deve nada aos privilégios ligados à origem social ou às especificidades da formação seguida. A vontade de ser preciso e analítico conduz ao estabelecimento de perfis extremamente detalhados, que têm em conta medidas antropológicas (peso e altura), mas também medidas da caixa craniana e do tórax), medidas fisiológicas (pulsos, pressão arterial, órgãos dos sentidos...) e medidas psicológicas (memória, inteligência, carácter). Estas medidas aferidas permitem construir um perfil que compreende aproximadamente cinquenta pontos.

perde a sua importância. Se é relativamente fácil medir as qualidades musculares de um trabalhador ou definir um nível óptimo de fadiga numa dada tarefa, é já mais difícil conhecer as qualidades necessárias para o exercício de todo o tipo de ofícios novos, como o de dactilógrafo, linotipista ou condutor de eléctricos. Como o sugeriam os estudos de Toulouse a propósito de Zola, os estudos de psicologia aplicada ao trabalho vão orientar-se para a procura dos sinais da superioridade profissional. Lahy (1872-1943), um dos colaboradores de Toulouse vai desenvolver estes trabalhos (Turbiaux, 1982). O seu carácter inovador reside no estabelecimento, para cada trabalhador implicado, de um conjunto de resultados detalhados, obtidos através de provas fisiológicas e psicológicas. Só os testes que têm uma correlação significativamente positiva com o valor profissional, previamente identificado, são retidos. Os trabalhos de Lahy têm sempre uma ancoragem social. Assim, depois de um estudo sobre os linotipistas em 1912, ele toma posição a favor do trabalho das mulheres e a favor da sua integração na vida sindical. No quadro da selecção profissional, se se trata de procurar a maior eficácia no trabalho, tal deve fazer-se respeitando as qualidades e as características de cada trabalhador. Nesta lógica, os primeiros aplicadores da psicologia aos problemas do trabalho são anti-tayloristas (Reuchlin, 1971).

A psicotécnica, uma resposta crítica ao taylorismo

Nos Estados Unidos, as primeiras aplicações relativas ao trabalho têm como origem, não um programa teórico mas as necessidades da indústria e o desejo de tornar a mão-deobra mais produtiva. Privilegiando os movimentos como mecanismos operatórios, por 
analogia aos de uma máquina, para eliminar todos movimentos parasitas e impor uma cadência abaixo da qual não se poderia cair, Taylor[ํㅣ desconhecia o homem. Como o sublinha Wallon, "pelo próprio carácter grosseiro dos seus procedimentos, que eram muitas vezes contrários à natureza fisiológica e psíquica do homem, o taylorismo levantou dificuldades e reacções que foram o ponto de partida para progressos importantes. Ele contribuiu finalmente a que se impusesse o que tendia a desconhecer ou a suprimir" (1930, p. 7) e acrescenta "a intervenção da psicologia (é) tão mais urgente quanto mais desconhecida" (p.13).

A resposta que Taylor (1911) traz à organização científica do trabalho inscreve-se numa perspectiva produtivista, segundo a qual o aumento do desempenho deve desencadear uma melhoria dos factores de satisfação dos trabalhadores. Há um tempo para sofrer e um tempo para gozar os frutos desse trabalho. Cada trabalhador deve empregar a sua força e a sua iniciativa "de maneira a dar o maior lucro possível ao seu patrão" (p.50). Aquele que produz mais ganha mais. A cada trabalho corresponde um certo número de movimentos adaptados, que se trata de reconhecer, de seleccionar, de ensinar e de impor. Taylor propõe que se levante a opacidade do trabalho, ele propõe que se torne o trabalho visível para o medir, abrindo a caixa negra do

trabalho. Trata-se de compreender o que fazem os trabalhadores quando trabalham. Há que extrair da cabeça e das mãos do trabalhador os seus saberes-fazer e os seus jeitos de mãos para os transferir aos gabinetes de métodos, que os vão racionalizar e traduzir em fórmulas matemáticas. Para Taylor, o pensamento complica as coisas. Ele propõe aos trabalhadores que se libertem do pensamento na aç̧ão para simplificar a sua vida. Só o trabalho produtivo que se traduz economicamente conta. Taylor definiu a produtividade como sendo a das operações concretas e, mais particularmente, a produtividade dos gestos. $O$ gabinete de estudos regula tudo e, entre os trabalhadores, nenhuma "solidariedade de interesses" é admitida.

Lahy reagiu desde a primeira tentativa de aplicação do taylorismo em França às fábricas Renault. As suas críticas estão todas contidas num livro escrito a partir de 1914, mas que só será editado em 1916. Em Taylor e Lahy, há uma mesma relação ao positivismo: a ciência é o instrumento do racionalismo. O que difere é a intenção. "Taylor quis construir no abstracto um trabalhador-tipo, trabalhando numa fábricatipo, com ferramentastipo" (p.177). Ora este trabalhador não corresponde à ideia que tem Lahy do trabalhador moderno "inteligente, activo, cheio de iniciativa, criador na esfera das suas competências" (p.177). o objectivo de Taylor é o rendimento, o rendimento do homem, sendo que este é pensado à semelhança do rendimento da máquina. Taylor pensa o homem como engenheiro e não como fisiologista, como psicólogo ou como sociólogo. "Nem por um minuto ele imaginou que os grupos sociais poderiam existir fora da fábrica e que a sua acção seria tão necessária ao homem quanto o seu ganha-pão" (p.179) - afirma Lahy e conclui - "um erro de método fê-lo aplicar ao estudo do trabalho humano os mesmos procedimentos que empregou para o estudo do trabalho mecânico" (p.180).

31 A psicotécnica, uma psicologia aplicada ao serviço do homem no trabalho e da orientação profissional

Lahy tira da sua crítica ao taylorismo várias conclusões: 

jogo funções psíquicas; ora, o estudo do trabalho intelectual não está acabado e os métodos de investigação neste domínio devem ser renovados" (p.187).

trabalho tem uma grande complexidade, "a solução trazida aos problemas que ele levanta resultará do contributo de diversas ciências e não de verdades fragmentárias de uma delas" (p. 188).

- o estudo do trabalho não pode ser conduzido em laboratório mas "num contexto determinado, o contexto de trabalho" (p.191). Impõe-se, portanto, "a observação directa, a experimentação nas condições normais da vida de trabalho em questão." (p. 189). Com efeito, "as condições extrínsecas do trabalho, a rapidez, as emoções que o acompanham, o aborrecimento, o

ritmo imposto, o constrangimento moral, são causas que escapam às pesquisas de laboratório e que determinam os mais graves acidentes para o trabalhador" (p.192).

Dessas conclusões, Lahy constrói o programa da psicotécnica: é necessário levantar para cada ofício o duplo problema da superioridade profissional e da fadiga. Há um bom método para medir o tempo, que deve ter em conta factores psicológicos e sociais. "A cronometragem não tem como único efeito forçar o trabalhador a despachar-se; ela pode também... aperfeiçoar a técnica" (p.57), permitindo ao trabalhador ser mais eficaz no seu trabalho. Trata-se para ele, de organizar a transmissão dos gestos mais adaptados. Agindo no curto prazo, degrada-se a longo prazo[ $\left.{ }^{10}\right]$. Colocar a psicologia ao serviço do trabalho, é essa a ambição de Lahy. Para ele, a psicotécnica é uma ciência que parte do terreno, da vida real, de onde ela extrai as suas observações e onde ela voltará inevitavelmente, portadora de aplicações concretas. Em 1933, na revista "Le Travail Humain" que ele acabara de criar com Laugier[11], ele clarifica a sua posição: "a análise do trabalho é a coisa mais longa e a mais difícil, já que coloca com precisão o problema científico. Pretender resolver um problema dessa ordem, sem a análise prévia do trabalho, seria como prescrever medicamentos a um paciente sem o ter examinado" (p.411).

39 Ele insurge-se contra a ideia, "infelizmente demasiado corrente que a psicotécnica assenta num conjunto de receitas muito simples e fáceis de aplicar. Em razão até do estado de desenvolvimento desta ciência, fazer psicotécnica, é fazer a todo o momento investigação" (p.411). Nesta lógica, Lahy e os seus colaboradores são os primeiros a ter praticado a análise psicológica do trabalho. Para eles, a análise do trabalho é uma condição prévia à selecção profissional.

40 As intenções de Lahy são difíceis de cumprir. Com o desenvolvimento da aplicação sistemática de testes, a análise do trabalho visando a sua adaptação ao homem foi, por vezes, esquecida. Com o retrocesso, parece efectivamente que o desvio entre as ambições sociais e científicas dos investigadores e as possibilidades de aplicação prática da psicotécnica foi demasiado importante. Neste contexto, pese embora o que ele diz na sua crítica do taylorismo, é inegável que Lahy subestimou a plasticidade dos indivíduos: o trabalhador que deve ter o conjunto das competências necessárias para o exercício do ofício. Contudo, a questão do desenvolvimento individual nunca o deixou tranquilo, como o testemunha a sua intervenção, em 1937, no II congresso internacional de higiene mental de Paris:

41 “constatámos que a inteligência se desenvolvia, por um lado, em função do exercício repetido que um meio cultivado impõe a cada indivíduo e, por outro lado, em função da

Laboreal, Volume $3 \mathrm{~N}^{\circ} 1$ | 2007 
cultura geral que uma sociedade bem organizada deve dispensar a todos os seus membros... a cultura geral constitui uma super-estrutura social que age sobre o indivíduo obrigando-o a progredir sem parar, sendo ela própria a consequência das actividades intelectuais de cada indivíduo" (1938, p. 289).

Mal instituída, os fundamentos da psicotécnica aplicada ao trabalho e à orientação profissional são interrogados. Do lado da selecção profissional, os progressos trazidos pelos métodos estatísticos permitiram mostrar que onde Piéron distinguia várias aptidões em séries de testes, havia na realidade apenas um só factor geral e vários factores específicos. Esta constatação não impedirá os testes de ter o sucesso que se lhes conhece. Tratando-se da psicotécnica aplicada à orientação escolar, a crise intervirá muito mais tarde. Mas isto é uma outra história, cujo vivido quotidiano dá ainda conta.

\section{Conclusão}

43 A psicologia da orientação e do trabalho é um bom exemplo do papel desempenhado pelo desenvolvimento das aplicações de uma ciência, no seu desenvolvimento e na sua instituição, no campo universitário. Essas aplicações,

"fornecem as razões e os meios de grandes desenvolvimentos metodológicos, incitandonos a examinar os fundamentos dos métodos e a pôr à prova a sua eficácia". Elas levam a ciência a explicitar as características que necessariamente a definem e, por essa via, a delimitar o domínio para além do qual não saberíamos legitimamente servirmo-nos dela" (Reuchlin, 1971, p. 49).

A psicotécnica constituída como ciência autónoma, as aplicações da psicologia vão poder diversificar-se e ser discutidas na sua relação com a ciência e a psicologia tornarse-á inteiramente uma disciplina universitária. A licenciatura em psicologia é criada em 1947 nas faculdades de letras ou de ciências, marcando assim a independência definitiva da psicologia, como disciplina autónoma, da filosofia e da fisiologia[ $\left.{ }^{12}\right]$. Desde então, a complementaridade entre uma psicologia geral e uma psicologia diferencial, herdeira da psicotécnica, vai progressivamente impor-se, mostrando a relação a estabelecer entre as teorias gerais do desenvolvimento e as diferenças individuais que se manifestam durante esse desenvolvimento. De maneira paradoxal, é no momento em que a prática psicológica atinge os seus próprios limites, que a investigação pode desenvolver-se no contexto universitário. A institucionalização da investigação universitária permite sair do quadro estreito da medida das aptidões e do estudo dos testes, para se interessar pelos modelos da psicologia geral e pela sua aplicação[13].

Como tentei mostrá-lo, três factores revelaram-se determinantes para as primeiras aplicações da psicologia e sua difusão:

- factores económicos e sociais, característicos do desenvolvimento industrial e das crescentes necessidades de qualificação do mundo da produção,

- factores científicos, ligados à procura de uma psicologia objectiva associando-se à consideração das diferenças individuais que permitem a cada um utilizar o melhor possível todos os seus recursos,

- factores ideológicos, que levam certos cientistas a crer que a ciência pode resolver os conflitos sociais e participar no desenvolvimento harmonioso dos homens e da sociedade.

Apesar da sua preocupação de justiça e de igualdade, as intenções dos primeiros investigadores no domínio da psicologia não deixam de ser contraditórias. Como o 
mostram bem Huteau e Lautrey (1979) a propósito da orientação profissional, as tentativas de racionalização do funcionamento social para afectar cada um ao seu lugar para felicidade de todos, puderam conduzir igualmente à denúncia das desigualdades como à sua justificação, e a vontade dirigista dos cientistas pôde, talvez, oporse ao ideal democrático que eles defendiam. Isto não é surpreendente, o desenvolvimento de uma ciência é, com efeito, em grande parte, dependente da flutuação das condições económicas da sociedade. Assim, para Foucault (1957), em psicologia, quando as condições de uma prática racional e científica não estão reunidas, por exemplo em caso de desemprego ou de degradação das condições de vida, é a própria ciência que é comprometida na sua positividade. A partir desta constatação, é difícil pronunciar-se de maneira definitiva sobre a influência que pôde ter um grupo de investigadores sobre a evolução das ideias e o desenvolvimento de uma disciplina universitária como a psicologia. Para além desta chamada de atenção, o objectivo desta conferência era darvos alguns pontos de referência relativamente à afirmação da psicologia como disciplina em França. É o grande mérito da história: iluminar-nos sobre este passado para nos ajudar a melhor compreender o presente e a agir. Nesta história, extraímos as razões de repensar de maneira dinâmica as ligações entre psicologia do trabalho e psicologia da orientação[ $\left.{ }^{14}\right]$. A psicologia deveria tirar proveito desta confrontação.

\section{Bibliografia}

Binet, A. \& Simon, T. (1909). L’année psychologique, 15, 1-147. Binet, A. (1908). Préface. L'année psychologique, $14, \mathrm{~V}-\mathrm{VI}$.

Clot, Y. (1999). La fonction psychologique du travail. Paris: PUF.

Comte, A. (1852/1971). Catéchisme positiviste. Paris: Editions Anthropos.

Crindal, A. \& Ouvrier-Bonnaz, R. (2006). La découverte professionnelle: guide pour les enseignants, les conseillers d'orientation-psychologues et les formateurs. Paris: Delagrave. Pédagogie et Formation.

Foucault, M. (1957). La recherche scientifique et la psychologie. In J.-E. Morère (eds). Des chercheurs français s'interrogent. Orientation et organisation du travail scientifique en France (165-186). Toulouse: Privat. Repris dans " Dits et écrits 1, 1954-1975 » en 1994. Paris: Gallimard.

Huteau, M. \& Lautrey, J. (1979). Les origines et la naissance du mouvement d'orientation. L'Orientation Scolaire et Professionnelle, 8, 1, 3-43.

Huteau, M. (2002). Edouard Toulouse et les débuts de la psychotechnique en France. Psychologie et Histoire, 3, 28-50.

Lahy, J.-M. (1916). Le système Taylor et la physiologie du travail professionnel. Paris: Editeurs Masson \& Cie.

Lahy, J.-M. (1933). Le premier laboratoire psychotechnique ferroviaire français aux chemins de fer du Nord. Le Travail Humain, Vol 1, 409431.

Lahy, J.-M. (1938). L'hygiène mentale dans l'orientation professionnelle, Ilème Congrès international d'hygiène mentale, Paris, juillet 1937. (p.287-302). Cahors: Imprimerie A. Coueslant.

Legrand, L. (1961). L'influence du positivisme dans l'œuvre scolaire de Jules Ferry. Les origines de la laïcité. Paris: M. Rivière.

Léontiev, A. (1984). Activité, conscience, personnalité. Moscou: Editions du Progrès. 


\section{intellectuelle avec la név
d'éditeurs scientifiques.} activites-v3n2.pdf

ris: H. Dunod et E. Pinat. Paris: Doin. Tome XXXVI, 362, 969-985.

Martinand, J.-L. (1986). Connaître et transformer la matière. Paris-Berne: Peter Lang.

Ouvrier-Bonnaz, R. \& Werthe, Ch. (2006). La référence au travail en classe de technologie: un débat de métier. @ctivités, 3 (2), 15-26, http://www.activites.org/v3n2/

Ouvrier-Bonnaz, R. \& Verillon, P. (2002). Connaissance de soi et connaissance du travail dans la perspective d'une didactique de l'orientation scolaire: une approche par la coanalyse de l'activité des élèves. Revue Française de Pédagogie, 141, 67-75.

Prot, B. \& Ouvrier-Bonnaz, R. (coord.) (2007). Activité d'orientation et

développement des métiers. Education Permanente, 171.

Reuchlin, M. (1971). Naissance de la psychologie appliquée. In M. Reuchlin, Traité de psychologie appliquée, 1. Paris: PUF.

Taylor, F.-W. (1911). Principes d'organisation scientifique des usines. Pa-

Toulouse, E. (1986). Enquête médico-psychologique sur les rapports entre la supériorité Toulouse, E. (1921). La question sociale. Paris: Edition du Progrès civique.

Toulouse, E., Piéron, H. \& Vaschide, N. (1904). Technique de psychologie expérimentale.

Turbiaux, M. (1982). J.-M. Lahy, essai de bio-bibliographie. Bulletin de psychologie,

Wallon, H. (1930). Principes de psychologie appliquée. Paris: Armand Colin.

\section{NOTAS}

1. Laboratoire de psychologie de l'orientation. Institut National d'Etude du Travail et d'Orientation Professionnelle, Conservatoire National des Arts et Métiers (CNAM) - Paris. (Laboratório de psicologia da orientação. Instituto Nacional de Estudo do trabalho e de Orientação Profissional, Conservatório Nacional das Artes e Ofícios - Paris).

2. Crindal, A. \& Ouvrier-Bonnaz, R. (2006). La découverte professionnelle: guide pour les enseignants, les conseillers d'orientation-psychologues et les formateurs. Paris: Delagrave Pédagogie et Formation.

3. Em França, as duas primeiras Repúblicas tiveram uma existência muito curta: a I República durou doze anos, aquando da Revolução Francesa (1792-1804), a II República teve uma duração de quatro anos, de 1848 a 1852. A III República inscreveu definitivamente o país num regime democrático.

4. No seu "Catecismo positivista" (1852), Comte foi o primeiro a falar de uma religião da humanidade, uma religião sem Deus. São os homens e mais particularmente os grandes homens, aqueles que aperfeiçoaram a ordem universal, que devem ser objecto de culto. 
5. Cattell, que foi aluno de Wundt, deu, em 1890, o nome de teste a estas provas estandardizadas cujo resultado é estimado por comparação estatística entre os indivíduos que a ele são submetidos.

6. Sobre o seu túmulo, no cemitério de Montparnasse, está escrito sobre o seu nome: Psiquiatrasociólogo-escritor, Criador do Hospital Henri Rousselle.

7. Ele criou em 1928, o Institut National d'Orientation Professionnelle - INOP (Instituto Nacional de Orientação Profissional), depois de ter criado em 1921 o Institut de Psychologie dependente da Universidade de Paris e ao qual será associado o laboratório criado por Ribot em 1889. Em 1923, é nomeado professor no Collège de France na disciplina de fisiologia das sensações. Dirige, desde essa época, a revista "L'Année Psychologique", que publica numerosas actas de investigações e apresentações de obras.

8. O termo aparece pela primeira vez em 1903, provavelmente, por iniciativa de William Stern. Ele é constituído a partir da palavra grega psyché: alma e techné: técnica.

9. Frederick Taylor (1856 1915), engenheiro americano, concebeu e pôs em prática o que designou "Organização Científica de Trabalho". Os seus trabalhos conduziram ao desenvolvimento do trabalho em cadeia e à parcelização das tarefas, transformando os trabalhadores em simples executantes, no contexto de empresas mecanizadas. Uma das principais críticas que lhe é tecida prende-se com o facto de ter introduzido no mundo do trabalho uma separação radical entre os que concebem e os que produzem

10. Numa época onde numerosos trabalhos de análise do trabalho mostram o aumento da taylorização dos processos de produção de bens e de serviços e onde o reforço das prescrições procedimentais é amiúde pensado como a única resposta possível à deterioração das condições de trabalho, a crítica de Lahy mantém toda a sua pertinência.

11. Laugier, co-fundador do INOP com Piéron, em 1928, é nomeado, no mesmo ano, titular da disciplina de fisiologia do trabalho do Conservatoire National des Arts et Métiers - CNAM. Esta disciplina será transformada seguidamente na disciplina de ergonomia.

12. Um certificado de psicofisiologia emitido pelas faculdades de ciências é contudo necessário para a obtenção da licenciatura.

13. É necessário esperar por 1962 para que a Sociedade Francesa de Psicologia publique um código de deontologia que se aplica ao exercício da psicologia e por 1985 para a publicação da lei que leva à criação definitiva do estatuto de psicólogo.

14. Nós interrogamos esta ligação no artigo de apresentação do número, coordenado com Bernard Prot, de Junho de 2007 da revista Education Permanente, consagrado às actividades de orientação e ao desenvolvimento das profissões.

\section{AUTORES}

\section{RÉGIS OUVRIER-BONNAZ}

INETOP Conservatoire National des Arts et Métiers (CNAM) 41, rue Gay Lussac, 75005 Paris France ouvrier-bonnaz@cnam.fr 